\title{
Editorial
}

Digestion

\section{Gastric Electrical Stimulation for the Treatment of Gastroparesis: Ready for Prime Time?}

\author{
D. Ang J. Tack
}

Department of Gastroenterology, University Hospital Gasthuisberg, Katholieke Universiteit Leuven, Leuven, Belgium

Gastroparesis is a symptomatic chronic disorder of gastric motility characterized by severely and chronically delayed gastric emptying without any evidence of mechanical obstruction [1]. The clinical presentation can vary from mild intermittent nausea to refractory vomiting, chronic abdominal pain, and a compromised nutritional state. In severe cases, total parenteral nutrition or a feeding jejunostomy may be required. Poorly controlled symptoms often lead to frequent hospital visits and contribute to an impaired quality of life.

The treatment of gastroparesis remains a clinical challenge. The currently available standard medical therapy is based on the use of anti-emetics and prokinetic agents, although the evidence for the efficacy of this therapy is not impressive. In addition, based on uncontrolled studies, intrapyloric injection of botulinum toxin seems able to relieve the symptoms of gastroparesis [2, 3], but preliminary controlled data do not confirm efficacy [4]. Where medical therapy fails, surgery is considered, and there are anecdotal reports of favourable outcomes with creation of a stoma, to provide access for enteral nutrition and decompression, or with major gastric resections reserved as a last resort [5].

In the light of the unsatisfactory results from conventional medical therapy, there has been growing interest in the use of gastric electrical stimulation (GES) as a treatment option. The development of an implantable gastric stimulator, using low-amplitude and high-frequency stimulation, which received the Food and Drug Administration approval as a humanitarian device in March 2000 (Enterra; Medtronic, Minneapolis, Minn., USA), provided a potentially attractive alternative for medical or surgical treatment of difficult gastroparesis.

To date, the beneficial effects of GES that have been reported from uncontrolled case series include improvements in nutritional status and symptoms of nausea and vomiting as well as improved quality of life [6-14]. In addition, a pilot study on the use of GES in patients with postgastric surgery gastroparesis showed improvements in symptoms and gastric emptying times at 1-year followup [15]. Favourable results with the use of GES in patients with intractable vomiting regardless of whether gastric emptying was delayed or normal have been recently reported [16]. However, many of these reports have included small patient numbers $(<30)[6-8,11,14-16]$, and in an uncontrolled use, the results may be influenced by a natural history with spontaneous improvement and by placebo effects. In addition, there are insufficient longterm data, with only two studies $[14,17]$ providing 3 -year results.

In this issue, Anand et al. [18] report on the largest series of 214 patients with drug-refractory gastroparesis followed up for a median duration of 4 years in three regional centres. The patients were divided into three

\section{KARGER}

Fax +4161306 1234

E-Mail karger@karger.ch

www.karger.com
(C) 2007 S. Karger AG, Basel

0012-2823/07/0753-0080\$23.50/0

Accessible online at:

www.karger.com/dig
J. Tack

Department of Gastroenterology, University Hospital Gasthuisberg

Katholieke Universiteit Leuven, Herestraat 49

BE-3000 Leuven (Belgium)

Tel. +32 1634 4225, Fax +32 34 4419, E-Mail jan.tack@med.kuleuven.be 
groups: (1) group 1 comprised 25 patients who consented to but did not receive a GES implant due to reimbursement issues; (2) group 2 comprised 156 patients with permanent GES implants, and (3) group 3 comprised 33 patients with temporary implants. The authors report a significant reduction in both nausea and vomiting, reduced total symptom scores, and enhanced gastric emptying in the patients who received GES at the latest follow-up as compared with baseline. Life table analysis results showed no survival benefits in patients who received GES as compared with non-implanted patients.

Although the findings from this paper suggest that GES implantation conveys long-term persisting benefits, no comparison data on symptom scores and quality-oflife measurements are available for the non-implanted patients (control group) at baseline and at latest followup. It is assumed that the control group received standard medical therapy, and it is conceivable that similar beneficial effects could have occurred. Furthermore, information on the long-term outcome of severe gastroparesis is very scarce in the literature, but follow-up case series of patients with intractable diabetic or idiopathic gastroparesis who require tube feeding suggest an overall improvement over time, with ability to resume oral feeding $[19,20]$. Similar to earlier reported studies, in the absence of a control arm, a contribution of a placebo effect in the treatment arm also cannot be excluded. To date, the multicentre Worldwide Anti-Vomiting Electrical Stimulation Study (WAVESS) [11] is the only randomized double-blind crossover trial reported. In the first part of the study, which was double blinded, there was a significant reduction in the vomiting frequency during the month, when the device was in the 'on' mode as compared with the 'off' mode, but the overall symptom score did not differ between both modalities. Moreover, the efficacy on the vomiting frequency seemed to be confined to the diabetic gastroparesis subgroup. During the second part of the study, which was open labeled, significant improvements in vomiting and quality of life were reported at 6 and 12 months. However, this trial involved a small number of patients ( 33 in total), having mixed idiopathic and diabetic gastroparesis, and the duration of the doubleblind arm of the study was restricted to only 2 months. The authors of the WAVESS trial [11] recommended that 'future protocols should include a postoperative recovery time of 1 to 3 months before randomization, and that electrical stimulation in placebo-controlled studies be extended to at least 3 months'. Unfortunately, results of newer studies of this type have not been reported until now.

Editorial
Various theories have been postulated concerning the mechanism of action of GES. These include altered autonomic nervous system tone, altered enteric nervous system function, reduced gastric sensitivity to gastric distension, and enhanced fundal relaxation [21-23]. However, the pathophysiological pathways that are directly implicated in the symptomatic improvement from GES remain unknown. Despite the reported improvement in nausea and vomiting and a selection of patients with proven gastroparesis, there is little or no correlation between symptom improvement and objective assessment of accelerated gastric emptying. No data are available on the effects of GES on the gastric contractility patterns. Undeniably, these findings highlight the present status of our ignorance of the mechanisms of action of GES. In the setting of such unknown mechanisms of action, a placebo effect cannot be ruled out, and the optimal mode and site of stimulation remain unclear.

Only one study has compared medical therapy to GES, but this was done in a non-randomized setting [14]. Whilst this study reported improved long-term symptom control and a decreased use of health care resources in the GES-treated group for up to 3 years of follow-up, the extremely small sample size ( 9 patients in each treatment arm), the unusually high mortality rate in the medical therapy group, and the lack of population-based control data were severe limitations of this study.

In the absence of convincing evidence of efficacy, and lack of good predictors of responsiveness, all patients undergoing Enterra implantation should preferably be involved in a follow-up program to document short- and long-term outcomes and to contribute to the scientific basis for this treatment. With that respect, Anand et al. [18] certainly must be commended for providing the largest and longest follow-up study reported to date. Still, many burning questions remain, before we can convincingly conclude that GES is efficacious and ready for generalized application. Except for the WAVESS study [11], none of the other studies have utilized wellcontrolled trial designs. Given the high costs involved (approximately USD 20,000.00), the unknown mechanism of action, and the absence of rigorous well-controlled randomized trials, we should exercise caution before embracing GES as a standard of care. Taking into account the unpredictable nature of gastroparesis and the poorly studied natural history, more long-term studies would be welcome, in addition to properly designed, well-controlled, randomized placebo-controlled studies, before we can draw scientific and objective conclusions.

Digestion 2007;75:80-82 


\section{References}

1 Parkman HP, Hasler WL, Fisher RS; American Gastroenterological Association: American Gastroenterological Association technical review on the diagnosis and treatment of gastroparesis. Gastroenterology 2004;127: 1592-1622.

2 Ezzeddine D, Jit R, Katz N, Gopalswamy N, Bhutani MS: Pyloric injection of botulinum toxin for treatment of diabetic gastroparesis. Gastrointest Endosc 2002;55:920-923.

3 Miller LS, Szych GA, Kantor SB, Bromer MQ, Knight LC, Maurer AH, Fisher RS, Parkman HP: Treatment of idiopathic gastroparesis with injection of botulinum toxin into the pyloric sphincter muscle. Am J Gastroenterol 2002;97:1653-1660.

4 Arts J, Caenepeel P, Degreef T, Verbeke K, Tack J: Randomised double-blind cross-over study evaluating the effect of intrapyloric injection of botulinum toxin on gastric emptying and symptoms in patients with gastroparesis (abstract). Gastroenterology 2005; 128(Suppl 2):A81.

5 Watkins PJ, Buxton-Thomas MS, Howard ER: Long-term outcome after gastrectomy for intractable diabetic gastroparesis. Diabet Med 2003;20:58-63.

6 Abell T, Lou J, Tabbaa M, Batista O, Malinowski S, Al-Juburi A: Gastric electrical stimulation for gastroparesis improves nutritional parameters at short, intermediate, and long-term follow-up. JPEN J Parenter Enteral Nutr 2003;27:277-281.

7 McCallum RW, Chen JD, Lin Z, Schirmer $\mathrm{BD}$, Williams RD, Ross RA: Gastric pacing improves emptying and symptoms in patients with gastroparesis. Gastroenterology 1998;114:456-461.
8 Forster J, Sarosiek I, Delcore R, Lin Z, Raju GS, McCallum RW: Gastric pacing is a new surgical treatment for gastroparesis. Am J Surg 2001;182:676-681.

9 Abell T, Van Cutsem E, Abrahamsson $\mathrm{H}$ Huizinga J, Konturek J, Galmiche J, Voeller G, Filez L, Everts B, Waterfall W, Domschke W, Bruley des Varannes S, Familoni B, Bourgeois I, Janssens J, Tougas G: Gastric electrical stimulation in intractable symptomatic gastroparesis. Digestion 2002;66:204-212.

10 Forster J, Sarosiek I, Lin Z, Durham S, Denton S, Roeser K, McCallum RW: Further experience with gastric stimulation to treat drug-refractory gastroparesis. Am J Surg 2003;186:690-695.

11 Abell T, McCallum RW, Hocking M, Koch K, Abrahamsson H, Leblanc I, Lindberg G, Konturek J, Nowak T, Quigley E, Tougas G, Starkebaum W: Gastric electrical stimulation for medically refractory gastroparesis. Gastroenterology 2003;125:421-428.

12 Lin Z, Forster J, Sarosiek I, McCallum RW: Effect of high-frequency gastric electrical stimulation on gastric myoelectric activity in gastroparetic patients. Neurogastroenterol Motil 2004;16:205-212.

13 Lin Z, Forster J, Sarosiek I, McCallum RW: Treatment of diabetic gastroparesis by highfrequency gastric electrical stimulation. Diabetes Care 2004;27:1071-1076.

14 Cutts TF, Luo J, Starkebaum W, Rashed H, Abell $\mathrm{T}$ : Is gastric electrical stimulation superior to standard pharmacologic therapy in improving GI symptoms, health care resources, and long-term health care benefits? Neurogastroenterol Motil 2005;17:35-43.

15 Oubre B, Luo J, Al-Juburi A, Voeller G, Familoni B, Abell T: Pilot study on gastric electrical stimulation in surgery-associated gastroparesis: long-term outcome. South Med J 2005;98:693-697.
16 Gourcerol G, Leblanc I, Leroi A, Denis P, Ducrotte P: Gastric electrical stimulation in medically refractory nausea and vomiting. Eur J Gastroenterol Hepatol 2007;19:29-35.

17 Lin Z, Sarosiek I, Forster J, McCallum RW: Symptom responses, long-term outcomes and adverse events beyond 3 years of highfrequency gastric electrical stimulation for gastroparesis. Neurogastroenterol Motil 2006;18:18-27.

18 Anand C, Al-Juburi A, Familoni B, Rashed $\mathrm{H}$, Cutts T, Abidi N, Johnson W, Minocha A, Abell TL: Gastric electrical stimulation is safe and effective: a long-term study in patients with drug-refractory gastroparesis in three regionalcenters. Digestion 2007;75:8389.

19 Vandenbroucke K, Kindt S, Demedts I, Tack $\mathrm{J}$ : Outcome of percutaneous jejunal feeding tube placement for refractory idiopathic severe gastroparesis: a retrospective review (abstract). Acta Gastroenterol Belg 2006;69: D14.

20 Fontana RJ, Barnett JL: Jejunostomy tube placement in refractory diabetic gastroparesis: a retrospective review. Am J Gastroenterol 1996;91:2174-2178.

21 Luo J, Rashed H, Easton P, Voller G, Familoni J, Abell T: Long-term treatment with gastric electrical stimulation is associated with changes in neuro-enteric function (abstract). Am J Gastroenterol 2000;95:A2471.

22 Wang Z, Qian L, Ueno T, Chen J: Mechanisms of various gastric electrical stimulations (abstract). Gastroenterology 2000;118: A669.

23 Tack J, Coulie B, Van Cutsem E, Ryden J, Janssens J: The influence of gastric electric stimulation on proximal gastric motor and sensory function in severe idiopathic gastroparesis (abstract). Gastroenterology 1999; 116:A1090. 